\title{
The Impact of an Educational Intervention on Inflammatory Bowel Disease for Nurses in Brazil
}

\author{
Jaqueline Ribeiro de Barros ${ }^{1 *}$ (), Adriana Rivera-Sequeiros ${ }^{2}{ }^{(\mathbb{C}}$, Julio Pinheiro Baima ${ }^{1}$ (), \\ Fernanda Lofiego Renosto1 (), Rogerio Saad-Hossne ${ }^{3}$ (i), Ligia Yukie Sassaki1 ${ }^{(1)}$
}

\author{
${ }^{1}$ Department of Internal Medicine, Medical School, São Paulo State University (UNESP), Botucatu, Brazil \\ ${ }^{2}$ Department of Internal Medicine, San Juan de Dios del Aljarafe Hospital, Seville, Spain \\ ${ }^{3}$ Department of Surgery, Medical School, São Paulo State University (UNESP), Botucatu, Brazil \\ Email: jackbnurse@gmail.com
}

How to cite this paper: de Barros, J.R. Rivera-Sequeiros, A., Baima, J.P., Renosto, F.L., Saad-Hossne, R. and Sassaki, L.Y. (2020) The Impact of an Educational Intervention on Inflammatory Bowel Disease for Nurses in Brazil. Open Journal of Nursing, 10, 1178-1185.

https://doi.org/10.4236/ojn.2020.1012084

Received: October 28, 2020

Accepted: December 8, 2020

Published: December 11, 2020

Copyright (c) 2020 by author(s) and Scientific Research Publishing Inc. This work is licensed under the Creative Commons Attribution International License (CC BY 4.0).

http://creativecommons.org/licenses/by/4.0/

\begin{abstract}
Background: The inflammatory bowel disease nurse plays a key role in the multidisciplinary team. The aim of the study was to evaluate the inflammatory bowel disease knowledge before and after the educational intervention with nurses. Methods: A cross-sectional, descriptive and comparative study was performed from June to August 2016. The sample consisted of 26 nurses from the nursing staff of a public university hospital in São Paulo State, Brazil. The study was divided into three phases: pre-educational intervention, educational intervention and post-educational intervention (test application). A p-value $<0.05$ was considered to indicate statistically significance. Results: The study included 26 general nurses with an average of $9.20 \pm 5.78$ years of experience. There was an increase in safety in administering biological therapy after the course (from $33.34 \%$ to $78.26 \%$ ), and an increase in knowledge about the main inflammatory bowel disease symptoms $(64.29 \%$ vs $96.30 \%, \mathrm{p}$ $=0.0224)$, and about infliximab infusion $(35.71 \%$ vs $74.07 \%, p=0.0404)$. Conclusion: The educational intervention effectively contributed to the increase of knowledge of the nursing staff.
\end{abstract}

\section{Keywords}

Inflammatory Bowel Diseases, Knowledge, Nursing Education, Nurses, Continuing Education

\section{Introduction}

Inflammatory bowel diseases (IBD) are chronic inflammatory diseases of the gastrointestinal tract and include Crohn's disease and ulcerative colitis. In the last decades, an increase in IBD incidence and prevalence rates has been observed 
worldwide, especially in newly industrialized countries [1]. IBD usually progresses to disabling conditions, especially at a functional and emotional condition, which seriously deteriorates the patient's quality of life. In this sense, the new treatment strategies aim not only to block the progression of the disease and prevent intestinal damage, but also to reduce the disability and to restore the quality of life [2].

The course of the disease is influenced by multiple nutritional, emotional, microbiological, pharmacological and environmental factors that affect treatment success [3]. Beyond enhancing therapeutic adherence, the creation of a multidisciplinary team composed by gastroenterologists, colorectal surgeons, nurses, dieticians, psychologists, pharmacists, pathologists and radiologists specialized in IBD would be advisable [4]. Within this multidisciplinary framework, the role of IBD nurses is key as described in the first consensus document of the nurses of European Crohn's and Colitis Organization (N-ECCO). IBD nurses' work of effective coordination between the different health professionals and in the training of the patient as the main actor in the management of illness and in the decision-making process, among other responsibilities, makes it a fundamental link focusing the therapeutic success [5].

The IBD nurse plays a key role in the multidisciplinary team. The responsibility of the nurse is to provide information related to IBD and holistic support to patients and their families; to ensure the comfort of patients with fistulization protecting the integrity of the skin and managing fistula complications; provide support and education about nutrition; to help patients recognize and improve the symptoms of fecal incontinence; identify patients with sexual dysfunction and support them; give information about biological therapies; and to promote effective communication between doctors, patients and the multidisciplinary team, among other recommendations [5].

Therefore, training the nursing team in theoretical knowledge and behavioral skills to provide information about the disease, its complications and healthy lifestyles is of paramount importance and as an instrument for training and development of health professionals we can mention permanent health education, which is characterized by "learning at work, where learning and teaching are incorporated into the daily life of organizations and work" [6]. A research conducted in 2016 [7] reported that "continuing education is the best strategy for the development of knowledge, skills and practices enabling qualified and safe care for the patient and promoting the reduction of adverse events".

Thus, the aim of the study was to evaluate the impact of IBD educational intervention on nurse's knowledge through a test applied before and after the intervention.

\section{Methods}

A cross-sectional, descriptive and comparative study was performed from June to August 2016. The instrument to guide the methodology was Standards for 
Reporting Implementation Studies (StaRI) Statement [8]. The sample consisted of 26 nurses from the nursing staff of a public university hospital in São Paulo state, Brazil. The hospital is referral in several clinical and surgical diseases, including IBD, and the nursing staff was composed by 180 nurses and 780 nursing technicians. In total, 26 nurses participated in the study. The nurses worked in different parts of the hospital, such as the outpatient clinic, infusion center, endoscopy unit, clinical and surgical hospitalization units. The selection to participate in the study was according to an indication of the hospital nurse coordinator. Nurses who deal with IBD patients in clinical practice were preferred. The sample was intentional and not probabilistic. The inclusion criteria were being a nurse regardless of the length of experience and the exclusion criteria was nurse removed from their function for general reasons during the period of data collection. The goal of the course was improving knowledge about IBD, aiming to provide a high quality and safety nursing care.

The study was divided into three phases: pre-educational intervention (test application), educational intervention and post-educational intervention (test application). The test was formulated exclusively for this study based on to the experience of the IBD multidisciplinary team, consisted of ten multiple-choice closed questions to obtain quantitative and categorizing data, and was not validated by the authors before application. The test covered three topics on IBD: conceptual aspects (4 questions), aspects related to biological therapy such as pre-biological tests, indications and biological therapy use complications (4 questions); and assessment of specific knowledge about nursing care in IBD (2 questions). The same test was applied right after the educational intervention.

The educational intervention consisted of an expository-dialog class through audiovisual resources and case studies, held by an IBD multidisciplinary team composed of gastroenterologists, colorectal surgeons, nurses, dietitian and psychologist, totalizing a 20 hour-course divided in 2 days, composed with active methodology, carried out in the proper rooms of the hospital. The topics discussed as theoretical class were a) IBD diagnosis; b) Indications, drug administration and side effects of biological therapy; c) Treatment of perianal Crohn's disease; d) The role and importance of the multidisciplinary team; e) Stomatherapy in IBD; and f) Discussion of clinical cases. Practical activities included nursing consultation with the staff, observation of the application of subcutaneous biological therapy, visit to the infusion center and to the endoscopy unit, as well as knowledge of the IBD unit's routine.

In addition, the impact of the educational intervention in IBD knowledge, from the participants' point of view, was assessed by rating a grade ranging from 0 : no impact to 10: great impact and the evaluation of the nurses about theoretical class, practical activities and composition of multidisciplinary team was also evaluated.

The local research ethics committee (2.499.244) approved the study and a written informed consent was obtained from the participation. 
The statistical analysis data are expressed as mean \pm standard deviation for continuous variables, and as frequency (proportion) for qualitative variables. The chi-square test and the Fisher's exact test, as appropriate, were used to compare categorical data. A p-value $<0.05$ was considered to indicate statistically significance. The data were coded, categorized, and typed in a Microsoft Excel $^{\oplus}$ spreadsheet. Later, they were exported, and the statistical analyses were performed using SAS version 9.3 for Windows (SAS Institute Inc., Cary, NC, USA).

\section{Results}

The study included 26 general nurses, $66.67 \%$ female with an average of $9.20 \pm$ 5.78 years of experience. Most professionals $(88.46 \%)$ participated in the care of patients with IBD, $76.92 \%$ reported knowledge about how many patients has been treated with biological therapy in the IBD unit, and 19.23\% reported previous experience with the subcutaneous application of adalimumab.

An increase in knowledge after the educational intervention was observed, specially about the signs and symptoms of IBD $(\mathrm{p}=0.0224)$ and infliximab infusion care $(p=0.0404)$. Regarding the assessment of disease activity, quality of life, extraintestinal manifestations and nursing consultation, a slight increase in knowledge was observed, as showed in Table 1.

There was an increase in safety in administering biological therapy after the course, from $33.34 \%$ to $78.26 \%$ of nurses reporting this issue. The education intervention course was evaluated as a high impact on IBD knowledge, receiving

Table 1. Analysis of the percentage of correct answers in the test between the pre and post educational intervention course.

\begin{tabular}{|c|c|c|c|}
\hline Questions & $\begin{array}{l}\text { Pre } \\
\text { educational } \\
\text { intervention }\end{array}$ & $\begin{array}{l}\text { Post } \\
\text { educational } \\
\text { intervention }\end{array}$ & p-value \\
\hline 1. What is the definition of Inflammatory Bowel Disease? & $85.71 \%$ & $77.78 \%$ & 0.8473 \\
\hline 2. Which diseases represent IBD? & $71.43 \%$ & $85.19 \%$ & 0.5232 \\
\hline 4. How can disease activity and quality of life of patients with IBD be evaluated? & $14.29 \%$ & $44.44 \%$ & 0.1132 \\
\hline $\begin{array}{l}\text { 5. Treatment with biological therapy aims to heal the intestinal mucosa, maintain remission of the disease } \\
\text { and improve quality of life. What are the necessary precautions with adalimumab? }\end{array}$ & $92.86 \%$ & $96.30 \%$ & 1.0 \\
\hline $\begin{array}{l}\text { 6. The nursing care systematization may occur in all public and private health services, in which professional } \\
\text { nursing care occurs. Which information the nurse should ask to patient during the nursing consultation? }\end{array}$ & $42.86 \%$ & $44.44 \%$ & 1.0 \\
\hline $\begin{array}{l}\text { 7. Extraintestinal manifestations occur in } 30 \% \text { of IBD patients. Some are related to disease activity and } \\
\text { others are independent of the inflammation process. What are the main extraintestinal manifestations? }\end{array}$ & $21.43 \%$ & $48.15 \%$ & 0.185 \\
\hline 8. Are the ways of administration for adalimumab and infliximab, respectively? & $78.57 \%$ & $96.30 \%$ & 0.2081 \\
\hline 9. What is the minimum and maximum ideal time described in the literature for infliximab infusion? & $35.71 \%$ & $74.07 \%$ & 0.0404 \\
\hline $\begin{array}{l}\text { 10. What is the correct conduct if the patient present symptoms during infliximab infusion such as facial } \\
\text { flushing, dyspnea, dizziness, nausea and mild hypotension? }\end{array}$ & $28.57 \%$ & $37.04 \%$ & 0.8455 \\
\hline
\end{tabular}

IBD = Inflammatory bowel disease. 
Table 2. Evaluation of the nurses about the educational intervention course.

\begin{tabular}{ccc}
\hline Topics & Good & Excellent \\
\hline Theoretical class & $45.83 \%$ & $54.17 \%$ \\
Practical activities & $47.83 \%$ & $34.78 \%$ \\
Composition of multidisciplinary team & $34.78 \%$ & $65.22 \%$ \\
\hline
\end{tabular}

an average grade of $8.83 \pm 1.14$ ( 0 - 10 points). The participants evaluated the quality of the educational intervention course as good or excellent (Table 2). All of the participants (100\%) would recommend the course to the colleagues.

\section{Discussion}

Nursing care may be systematized and individualized to ensure comprehensive care for patients with IBD, in order to meet all patients' needs. The team should be properly oriented on the specificities of the disease to obtain satisfactory results, such as disease acceptance, treatment adherence and, consequently, maintenance of deep remission and reduction of complications, hospitalizations, surgeries and mortality rates, thus improving the patient's quality of life. Health education aims to contribute to the improvement of IBD centers and nurses are part of this complex process that includes caring, educating and managing [5].

According to the European consensus for nurse (N-ECCO), nurses caring for patients with IBD need basic knowledge of the diseases, such as the difference between ulcerative colitis and Crohn's disease, issues related to medications and surgical options, and the key diagnostic and treatment strategies [5]. Moreover, nurses need to know about how to measure the quality of life and activity disease, issues about biological therapy and the main extraintestinal manifestations [5]. The intervention course promoted an improvement in the IBD knowledge in the participating nurses, mainly in aspects related to IBD signs and symptoms and caring during the infusion of infliximab.

The sample was predominantly composed of gender female (66.67\%), consistent with the survey conducted by the Federal Nursing Council on the profile of nursing in Brazil [9].

Graduation courses do not provide the necessary skills the professionals require. Continuing education courses are important tools for training professionals involved with the disease. The educational intervention raises the participants' knowledge, assuring them theoretical and practical knowledge, favoring a trust relationship between the patient and the health professional [10].

IBD is a complex condition requiring expert nursing care and according to the European nursing consensus in IBD, nurses need to know basic knowledge about diseases, such as the difference between $\mathrm{CD}$ and $\mathrm{UC}$, how the diagnosis is made, treatment, also about the impact of IBD on patients' lives, and, about biological therapy, from screening to ensuring health maintenance [5]. In the present study, the majority of the participants related previous involvement with IBD patient care but demonstrate a low graded-knowledge about IBD basic as- 
pects such as disease definition, biological therapy and IBD nursing care.

IBD intensive training courses and continuing education programs should be stimulated to disseminate scientific learning about the disease throughout the country. Facing the increasing incidence of the disease, the inability of the health professionals to properly diagnose and establish the appropriate treatment of the disease within the window of opportunity may lead to the development of complications compromising the patient's quality of life.

Studies showed that the presence of an IBD nurse improve the quality of care [11] [12] and IBD nurses specialists are essential to the multidisciplinary team, composing the core team along with the medical team [13]. Medical and nurse's societies and health organizations should promote awareness initiatives about the importance of the presence of an IBD nurse in hospitals and the importance of teaching IBD in undergraduate and postgraduate courses across the country.

However, the study presented some limitations such as sample size, since it was an intentional sample since it was not performed with all nurses in the health institution, the type of study performed (cross-sectional) and the evaluation was performed with closed questions, resulting in limited information about knowledge in IBD.

\section{Conclusion}

IBD is a complex disease that can progress to functional disability. Nursing care education can improve IBD outcomes aiming at controlling patients' symptoms and quality of life. The educational intervention effectively contributed to the increase of knowledge of the nursing staff, demonstrating the validity of this type of intervention as an instrument of continuing education.

\section{Funding Sources}

This work was supported by the Coordenação de Aperfeiçoamento de Pessoal de Nível Superior-Brasil (CAPES)_Finance Code 001.

\section{Author's Contributors}

As corresponding author, I attest that all authors have contributed substantially to the paper and take responsibility for its contents. Jaqueline Ribeiro de Barros and Ligia Yukie Sassaki contributed to the conception and design of the study, acquisition, analysis and interpretation of data, drafting the article, revising it critically for important intellectual content and final approval of the version to be submitted. Julio Pinheiro Baima, Fernanda Lofiego Renosto and Rogerio Saad Hossne contributed to the acquisition, analysis and interpretation of data and revised it critically for important intellectual content. Adriana Rivera-Sequeiros revised it critically for important intellectual content. All authors have approved the final version submitted for publication and agreed for all aspects of work ensuring integrity and accuracy. 


\section{Acknowledgements}

We thank Eloisa Elena Pascoalinotte from Botucatu Medical School at São Paulo State University (UNESP) for the statistical review of the study. We thank CAPES for the pos-graduation scholarship offered to Jaqueline Ribeiro de Barros.

\section{Conflicts of Interest}

The authors declare no conflict of interest.

\section{References}

[1] Ng, S.C., Shi, H.Y., Hamidi, N., et al. (2017) Worldwide Incidence and Prevalence of Inflammatory Bowel Disease in the 21st Century: A Systematic Review of Population-Based Studies. The Lancet, 390, 2769-2778. https://doi.org/10.1016/S0140-6736(17)32448-0

[2] Colombel, J.F., Narula, N. and Peyrin-Biroulet, L. (2017) Management Strategies to Improve Outcomes of Patients with Inflammatory Bowel Diseases. Gastroenterology, 152, 351-361. https://doi.org/10.1053/j.gastro.2016.09.046

[3] Vedamurthy, A. and Ananthakrishnan, A.N. (2019) Influence of Environmental Factors in the Development and Outcomes of Inflammatory Bowel Disease. Gastroenterol Hepatol (N Y), 15, 72-82. http://www.ncbi.nlm.nih.gov/pubmed/31011301.

[4] Morar, P.S., Sevdalis, N., Warusavitarne, J., et al. (2018) Establishing the Aims, Format and Function for Multidisciplinary Team-Driven Care within an Inflammatory Bowel Disease Service: A Multicentre Qualitative Specialist-Based Consensus Study. Frontline Gastroenterology, 9, 29-36. https://doi.org/10.1136/flgastro-2017-100835

[5] Kemp, K., Dibley, L., Chauhan, U., et al. (2018) Second N-ECCO Consensus Statements on the European Nursing Roles in Caring for Patients with Crohn's Disease or Ulcerative Colitis. Journal of Crohn's and Colitis, 12, 760-776. https://doi.org/10.1093/ecco-jcc/jjy020

[6] Ministry of Health (Brazil), Office of the Minister (2004) Ordinance No. 198/GM/MS. Establishes the National Policy of Continuing Education in Health as a strategy of the Unified Health System for training and development of workers for the sector and provides other measures. Official Gazette of the Federal Republic of Brazil, Brasília/Distrito Federal.

http://bvsms.saude.gov.br/bvs/saudelegis/gm/2017/MatrizesConsolidacao/comum/1 3150.html

[7] Aruto, G.C., Lanzoni, G.M.M. and Meirelles, B.H.S. (2016) Best Practices in Care for People with Cardiovascular Diseases: The Interface between Leadership and $\mathrm{Pa}$ tient Safety. Cogitare Enfermagem, 21.

https://revistas.ufpr.br/cogitare/article/view/45648/pdf https://doi.org/10.5380/ce.v21i5.45648

[8] Borek, A.J., Abraham, C., Smith, J.R., Greaves, C.J. and Tarrant, M. (2015) A Checklist to Improve Reporting of Group-Based Behaviour-Change Interventions. BMC Public Health, 15, Article No. 963. https://doi.org/10.1186/s12889-015-2300-6

[9] Federal Nursing Council (2017) Nursing Profile in Brazil. Final Report. http://www.cofen.gov.br/perfilenfermagem/pdfs/relatoriofinal.pdf

[10] Macêdo, W.T.P., Figueiredo, B.M., Reis, D.S.T., Barros, S.H.P., Ramos, M.C.A.R. and Silva, S.E.D.S. (2019) The Nursing Professionals' Engagement to Educational 
Practices. Journal of Research Fundamental Care Online, 11, 1058-1064. https://doi.org/10.9789/2175-5361.2019.v11i4.1058-1064

[11] Coenen, S., Weyts, E., Vermeire, S., et al. (2017) Effects of Introduction of an Inflammatory Bowel Disease Nurse Position on the Quality of Delivered Care. European Journal of Gastroenterology \& Hepatology, 29, 646-650. https://doi.org/10.1097/MEG.0000000000000839

[12] Hernández-Sampelayo, P., Seoane, M., Oltra, L., et al. (2010) Contribution of Nurses to the Quality of Care in Management of Inflammatory Bowel Disease: A synthesis of the Evidence. Journal of Crohn's and Colitis, 4, 611-622. https://doi.org/10.1016/j.crohns.2010.08.009

[13] Panés, J., O’Connor, M., Peyrin-Biroulet, L., Irving, P., Petersson, J. and Colombel, J.F. (2014) Improving Quality of Care in Inflammatory Bowel Disease: What Changes Can Be Made Today? Journal of Crohn's and Colitis, 8, 919-926.

https://doi.org/10.1016/j.crohns.2014.02.022 